\title{
Correspondence
}

Editor: Ian Pullen

Contents: Unresolved grief/Long-stay psychogeriatric patients/Asian patients and the HAD scale/ HAD and ROC/CT findings in schizophrenia/ Chronic psychoses in Turner's syndrome/Aggressiveness, anxiety and drugs/Auditory hallucinations during oculogyric crises/Reviewing reviewers/Failure to convulse with ECT/Asian suicides/Olfaction and psychiatry/Pathological jealousy and pimozide/ Durkheim's views on suicide.

\section{Unresolved grief}

SIR: Nightingale (Journal, December 1989, 155, 862864) described a negative therapeutic reaction occurring as a result of unresolved grief. Each time the patient (Mrs A) experienced symptom relief during a psychodynamic therapy session, she later experienced a return of her depression. Psychodynamic mechanisms are proposed to explain this: in particular, object relations and the concept of 'triumph' over the lost object. 'Triumph', if particularly strong, may interfere with the process of reparation towards a loved object. Each time 'triumph' was experienced her guilt and symptoms returned.

An alternative explanation can be drawn from cognitive-behavioural approaches. Our clinical work with family members who have survived, and often witnessed, the death of a member by homicide reveals similar changes to Mrs A. Survivors are exposed to the seyerest psychological trauma. Symptoms of post-traumatic stress disorder (DSM-III-R, American Psychiatric Association, 1987) are common. Ruminations, nightmares, constant fear (which can generalise to severe social handicap), and physiological disturbances are also common. Belief in the world as a safe place is destroyed. The trauma results in new cognitive attributions about themselves and the world that can be understood without reference to psychodynamic conflict.

We would like to suggest that other factors, based on goal conflict, could explain the negative therapeutic reaction described. A number of behavioural goal-directed conflicts are readily evident from the brief case description. The ambivalence towards her husband was the result of an approach-avoidance conflict. She felt drawn towards him because he "showed ... the kind of care she never had at home", yet felt repelled because of his impotence. Continuing to accept his caring meant giving up children of her own-clearly a difficult dilemma. This conflict was not resolved when he was alive and would be evoked when he was remembered. Regarding her daughter, she is trapped in an avoidant-avoidant conflict. She wishes to avoid the stress of parenting the child but also wishes to avoid the feeling that she is uncaring. The approval of authority figures ('medical advice') helped resolve the conflict. However, this was overturned by the disapproval of a potentially more powerful figure (modelling theory; Bandura, 1969), a priest (given that she was a "deeply religious woman").

It is likely that this experience led her to a belief that one must be stricken by loss, even of ambivalently regarded objects, if one is to be a good person and obtain the approval of powerful figures. Grief itself becomes an approach - avoidance conflict. To experience relief she must endorse the belief that she is a bad person, which she wishes to avoid. To be a good person she must experience grief, which she also wishes to avoid. The changes seen in therapy ('triumph' and later symptom recurrence) can be viewed as movement between equally desirable but mutually exclusive goal states. Resolution of the conflict likely occurred with a cognitive shift, (explicitly or implicitly reinforced by the therapist - an authority figure), that the previous belief was erroneous. We also suspect that the power of authority figures was enhanced by a set of learned self-attributions that she was inadequate, a result of previous learning within a family that modelled inadequacy (e.g. her father) and failed to provide esteem building feedback ("was not close").

Conditioned responses may also play a part in grief. For example, a knock at the door or a telephone ringing may become associated with the news (or witnessing) of a loss (conditioned emotional reaction). The stimuli elicit avoidant responses, and through generalisation 'avoidance' permeates the survivors life (Amick-McMullan et al, 1989). Avoidant reactions may also effect psychotherapeutic 
endeavours - talking about a loss (and other losses) may elicit avoidance reactions and seeming lack of progress in therapy. Exploring Mrs A's automatic thoughts (Beck et al, 1979) when she experienced relief may have helped her uncover dysfunctional thinking.

We believe it is too simplistic to consider only psychodynamic factors. These can be proposed as 'fundamental mechanisms' to understanding. However, they are filtered through the executive and cognitive functions of the ego. Therefore previous learned cognitive attributional sets and conditioned responses must also be considered. All three mechanisms operate together in any case of grief and therapeutic work.

Geoffrey C. Fisher

Department of Psychiatry DOUGLAS MURDOCH

University of Calgary

Alberta, Canada

\section{References}

American Psychiatric Association (1987) Diagnostic and Statistical Manual of Mental Disorders (DSM-III-R) (3rd edn, revised). Washington, DC: APA.

Amick-McMullan, A., Kilpatrick, D. G. \& Veronen, L. J. (1989) Family survivors of homicide victims: a behavioral analysis. The Behavior Therapist, 12, 75-79.

BeCK, A. P., Rush, A. J., SHAw, B. F. et al. (1979) Cognitive Therapy of Depression. New York: Guilford Press.

BAndurA, A. (1969) Principles of Behavior Modification. New York: Holt Rinehart \& Winston.

SIR: Fisher \& Murdoch have reformulated the case material I presented (Journal, December 1989, 155, 862-864) and the mechanism of the patient's recovery using explanations drawn from cognitive and learning theory. I am grateful to them for their interest and in most respects I regard their theorising as compatible with my own. However, I would like to take issue over two points where our thinking diverges.

Firstly, they suggest that, as a result of her (earlier) experience of the disapproval of a powerful authority figure (a priest) at her seeming failure to mourn her daughter, Mrs A developed an approach-avoidance conflict regarding her grief whereby she believed that to experience relief she must endorse the belief that she was a bad person, which she wished to avoid. They go on to suggest that resolution of this conflict occurred with a cognitive shift (reinforced by the therapist) that the previous belief was erroneous. This explanation fails to take into account the importance of the patient's guilt over her aggressive feelings towards both her husband and daughter. Exploration of this, in psychodynamic psychotherapy, allowed her to express these feelings to the therapist and to face her fantasy that she was indeed a bad person. Interpretation to her of her unconscious fantasy that she was continuing to harm her husband (by triumphing over him) each time she experienced relief from her grief, allowed her to free herself from the vicious circle.

Secondly, I would wish to emphasise that the significance of authority figures in this patient's mental life lay in the way in which they interacted with her own internal world, that is with her internal objects. Exploration and interpretation of this was important in helping her to establish a less harsh view of herself and in freeing her from the need for self-punishment.

In summary then, I disagree with Drs Fisher \& Murdoch over their failure to consider the unconscious meaning of the patient's symptom pattern and the importance of the interaction between real external figures and the patient's internal objects.

Psychotherapy Unit

ANNE M. Nightingale

Royal Edinburgh Hospital

Morningside Park

Edinburgh EHIO SHF

\section{Long-stay psychogeriatric patients}

SIR: Hilton et al (Journal, December 1989, 155, 782786) provide useful cross-sectional data revealing very high levels of dependency among long-stay psychogeriatric patients compared with residents of a local authority home. However, another perspective can be provided by asking whether changes in levels of dependency have occurred over time.

In 1985, Norman, then of the Centre for Policy on Ageing, performed a survey in 14 facilities offering long-stay psychogeriatric care, including our own September ward (Norman, 1987). Dependency was rated using a subsection of the Crichton Royal Behaviour Rating Scale which has been found to correlate well with clinical assessment (Evans et al, 1981). The ratings were repeated in December 1989.

In the 1985 survey of our ward, before it was fully open, 15 patients attained a mean score of 8.5 (range 5-11). One patient scored the maximum dependency score (11). Furthermore, Norman reported that 'several' had difficulties with speech, no-one was totally chair-bound and four $(27 \%)$ required physical help with feeding. The mean score in December 1989 for 18 patients (the maximum number of beds was 20 but two deaths had occurred just before the ratings) was 9.6 (again, range 5-11). However, this 